04

\title{
Микроструктура искрового разряда в воздухе в промежутке острие-плоскость
}

\author{
( К.И. Алмазова, А.Н. Белоногов, В.В. Боровков, Е.В. Горелов, И.В. Морозов, А.А. Тренькин, \\ С.Ю. Харитонов
}

Российский Федеральный ядерный центр

Всероссийский научно-исследовательский институт экспериментальной физики, 607190 Саров, Россия

e-mail: trenkin@ntc.vniief.ru

(Поступило в Редакцию 16 октября 2017 г.)

\begin{abstract}
Методом теневого фотографирования обнаружена микроканальная структура искрового разряда в воздухе атмосферного давления в промежутке острие-плоскость, наблюдаемая с момента появления свечения разряда. Зарегистрирована динамика микроструктуры на временах от единиц до десятков наносекунд, включающая развитие микроканалов от острия вглубь разрядного промежутка, ветвление, расширение микроканалов и их взаимодействие. Установлена корреляция микроструктур искрового канала в разрядном промежутке и его автографа на поверхности плоского электрода.
\end{abstract}

DOI: 10.21883/JTF.2018.06.46011.2511

\section{Введение}

Широкое практическое применение и богатое разнообразие физических процессов, протекающих в высоковольтных импульсных газовых разрядах, обусловливают актуальность их исследований. С одной стороны, интерес представляют исследования самоорганизации пространственной структуры таких разрядов, поскольку она обусловливает характер и степень воздействия на газ. С другой стороны, весьма важным является вопрос воздействия разряда на электроды, определяющего характер и степень их эрозии.

Исследования в этих направлениях ведутся достаточно давно, однако несмотря на огромное количество работ, посвященных данной тематике, ряд явлений до сих пор мало изучен. Одно из них связано с возможным наличием микроканальной структуры токовых каналов и ее участием в газоразрядных процессах в плотных газах. Об этом свидетельствуют как результаты теоретических исследований [1-7], так и обнаруженная в ряде работ микроструктура автографов каналов на поверхности электродов [6-20]. Микроструктура представляет собой совокупность большого количества микрократеров диаметрами от 0.1 до $50 \mu \mathrm{m}$, распределенных по сечению автографа. Оптическими и электронно-оптическими методами внутренняя структура токового канала на фоне светящейся внешней оболочки была неразрешима $[6-9,12,17-20]$.

Согласно имеющимся представлениям, микроканальная структура формируется в начальной фазе пробоя за счет неустойчивости фронта волны ионизации, обладает высокой скоростью эволюции (единицы-десятки наносекунд) и сложной пространственной фор- мой $[1-9,15,20,21]$. Это обусловливает сложность регистрации микроструктуры, особенно в условиях функционирования высоковольтных установок.

Следует отметить, что ранее по интегральным фотографиям удавалось зарегистрировать свечение отдельных микроканалов лишь в прианодной области: в диффузном разряде в промежутке острие (катод)-плоскость с межэлектродным расстоянием $60 \mathrm{~mm}$, а также в многоканальном разряде в геометрии проволочка (катод)-плоскость с межэлектродным расстоянием $73 \mathrm{~mm}$ при пониженном давлении 220 Torr $[10,13]$.

Попытка зарегистрировать нитевидную структуру канала в начальной фазе разряда была предпринята в [16], где на кадрах скоростной фотосъемки вдоль длины канала прослеживались отдельные области повышенной интенсивности свечения. Однако система регистрации в этой работе не обеспечивала большого отношения полезный сигнал/шум и высокого пространственного разрешения.

Таким образом, полученные к настоящему времени экспериментальные данные по микроструктуре в объеме межэлектродного промежутка в основном носят косвенный характер.

Вместе с тем предполагаемые высокие удельные значения энерговклада в микроканалы и сопутствующие газодинамические эффекты $[9,12,15,20,21]$ обусловливают возможность регистрации микроструктуры методами теневого фотографирования. Следует отметить, что такие методы успешно применялись при исследованиях газоразрядных процессов [22-25].

Целью настоящей работы является исследование пространственной структуры в начальной фазе искрового разряда в воздухе атмосферного давления в геометрии острие-плоскость методом теневого фотографирования. 


\section{Экспериментальная аппаратура и методика}

Эксперименты проводились на стенде, включающем генератор импульсов напряжения (ГИН), кабельную линию, разрядный промежуток, диагностическую аппаратуру и систему синхронизации (рис. 1).

Генерация импульсов напряжения обеспечивалась коммутацией заряженной емкости на кабельную линию. Амплитуда напряжения на выходе ГИН составляла $25 \mathrm{kV}$, длительность фронта импульса напряжения по уровню $0.1-0.9$ составляла $7 \mathrm{~ns}$, разброс времени срабатывания ГИН составлял $\pm 1.5 \mathrm{~ns}$.

Кабельная линия волновым сопротивлением $60 \Omega$ имела длину $5.5 \mathrm{~m}$ и нагружалась на разрядный промежуток острие-плоскость. Электрод-острие длиной $5 \mathrm{~cm}$ и диаметром $15 \mathrm{~mm}$ изготовлен из алюминиевого сплава. Угол при вершине острия $80^{\circ}$, радиус кривизны $0.2 \mathrm{~mm}$. Плоским электродом служила пластина толщиной $2 \mathrm{~mm}$ и размером рабочей поверхности $50 \times 20 \mathrm{~mm}^{2}$. В качестве материала пластины использовались алюминиевый сплав, техническая медь или сталь. Межэлектродный зазор составлял $3.5 \mathrm{~mm}$.

В экспериментах регистрировались напряжение и ток на выходе ГИН. Измерение напряжения $U$ осуществлялось емкостным делителем, тока $I$ - резистивным шунтом. Регистрация напряжения и тока выполнялась с помощью цифрового осциллографа.

Система оптической регистрации включала в себя источник зондирующего излучения - лазер, объектив и цифровую электронно-оптическую камеру. Плоскопараллельный пучок лазерного излучения, проходя через область разряда перпендикулярно оси электрода-острия, регистрировался электронно-оптической камерой. Изображение разрядного промежутка переносилось на цифровую камеру с десятикратным увеличением. В некоторых экспериментах в оптической схеме использовался нож Фуко, располагаемый в фокусе объектива. Система регистрации обеспечивала пространственное разрешение не хуже $5 \mu \mathrm{m}$. Следует отметить, что в поле зрения системы оптической регистрации попадала примерно половина межэлектродного зазора.

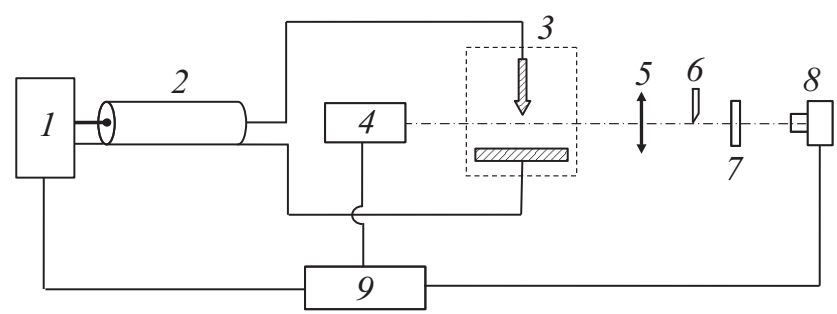

Рис. 1. Схема экспериментального стенда. 1 - ГИН, $2-$ кабельная линия, 3 - разрядный промежуток, 4 - источник зондирующего сигнала (лазер), 5 - объектив, 6 - нож Фуко, 7 - светофильтры, 8 - электронно-оптическая камера, 9 блок синхронизации.
В качестве источника зондирующего излучения использовался твердотельный лазер с длиной волны $532 \mathrm{~nm}$. Максимальная энергия в импульсе около $25 \mu \mathrm{J}$. Длительность импульса на полувысоте составляет $6 \mathrm{~ns}$, джиттер - $1.5 \mathrm{~ns}$. В области формирования разряда поперечный размер лазерного пучка составлял примерно $1 \mathrm{~cm}$ и имел гауссов профиль.

Съемка электронно-оптической камерой велась в однокадровом режиме. Экспозиция составляла $130 \mathrm{~ns}$, что заметно превосходило длительность лазерного излучения и могло быть причиной влияния собственного свечения разряда на тенеграммы. Для снижения этого эффекта при визуализации начальной стадии разряда момент запуска лазера выбирался ближе к закрытию электронно-оптического затвора. Интервал времени между окончанием лазерного импульса и закрытием затвора составлял примерно $10 \mathrm{~ns}$. В этом случае значительная часть времени экспозиции опережала начало формирования разряда. Для дополнительного ослабления свечения разряда на входе электронно-оптической камеры располагались светофильтры.

Варьированием момента запуска ГИН относительно запуска лазера обеспечивалась визуализация различных стадий разрядного процесса. Временна́я привязка кадра в каждом импульсе осуществлялась по осциллограммам напряжения и тока разряда, контрольным сигналам лазера и цифровой электронно-оптической камеры с учетом длин электрических и световых линий.

В некоторых экспериментах одновременно с оптической регистрацией пространственной структуры разряда регистрировался его автограф на поверхности плоского электрода. Для этого рабочая поверхность электрода полировалась пастой ГОИ. Регистрация проводилась в режиме однократного импульса. Автограф визуализировался посредством оптического микроскопа.

\section{Экспериментальные результаты и их обсуждение}

После пробоя промежутка в разрядной цепи возникал колебательный процесс с экспоненциальным затуханием тока и напряжения. Длительность полуволны составляла $0.5 \mu \mathrm{s}$, амплитуда тока и время его затухания соответственно - $1.5 \mathrm{kA}$ и $2 \mu \mathrm{s}$. За момент пробоя условно принят момент начала роста тока и соответственно спада напряжения.

На рис. 2 представлены тенеграммы разряда в различные моменты времени относительно пробоя. Видно, что канал разряда представляет собой пучок микроканалов, примерно эквидистантно распределенных в плоскости изображения. Минимальные диаметры микроканалов в начальной фазе находятся на границе пространственного разрешения системы регистрации. Это может означать наличие в разрядном промежутке микроканалов меньших диаметров, не визуализируемых на тенеграммах. 
$a$

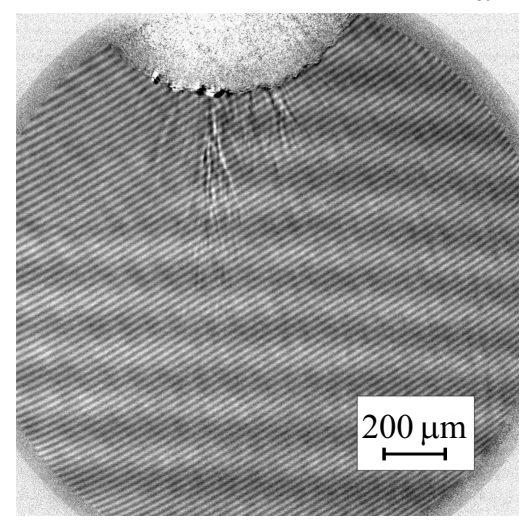

$b$

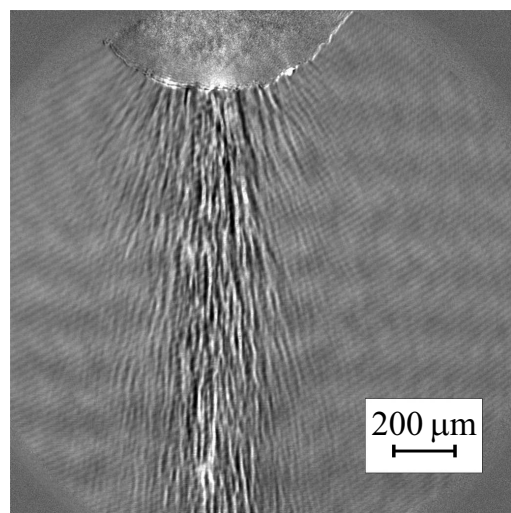

C

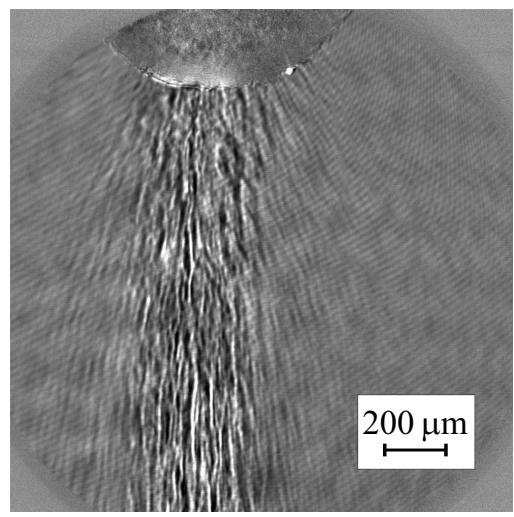

Рис. 2. Тенеграммы разряда в различные моменты времени относительно начала пробоя: $a-0, b-15, c-25 \mathrm{~ns}$. Электродострие находится сверху.

Средний диаметр микроканалов, оцененный по тенеграмме, соответствующей 15 -й ns, составляет примерно $15 \mu \mathrm{m}$. Оценка общего числа микроканалов в предположении, что они расположены эквидистантно по сечению канала, дает значение 200-400. Необходимо отметить, что микроструктура наблюдается на тенеграммах, начиная с момента появления свечения разряда, которое раньше всего возникает вблизи острия. В то же время в отсутствие подсвечивающего лазерного излучения на тех же стадиях разряда микроканалы на фотографиях свечения разряда не различимы (рис. 3).

Тенеграммы различных стадий разрядного процесса позволяют качественно проследить эволюцию микроструктуры. Видно, что стартующие от электрода-острия микроканалы интенсивно ветвятся в направлении от острия (рис. $2, a$ ). Со временем диаметр микроканалов растет и уже на 15-25-й ns они начинают взаимодействовать друг с другом (рис. $2, b$ и $2, c$ ). Этот процесс начинает развиваться вблизи электрода-острия и затем распространяется вглубь разрядного промежутка. После $50 \mathrm{~ns}$ структура внутри канала становится хаотичной, отдельные протяженные микроканалы не регистрируются, a на 80-й ns на границе канала разряда формируется ударная волна.

На рис. 4 представлено изображение автографа канала на поверхности плоского медного электрода. Видно, что отпечаток канала представляет собой скопление микрократеров диаметрами от 5 до $35 \mu \mathrm{m}$. Данное значение коррелирует с диаметрами микроканалов в объеме разрядного промежутка, а диаметр автографа соответствует диаметру канала. Количество уверенно различимых микрократеров составляет около 80. Эту величину следует рассматривать как оценку снизу ввиду относительно малой кратности увеличения изображений и низкого качества полировки поверхности электрода. Кроме того, относительно высокий ток разряда в настоящих экспериментах приводит к тому, что многие микрократеры сливаются друг с другом, формируя единый эрозионный след. В центральной части изображения автографа наблюдается совокупность микрократеров, образующих квазиконцентрическую кольцевую структуру. Такая структура эрозионных пятен регистрировалась ранее в разряде подобного типа [19].

Для исследования зависимости наличия микроструктуры от величины тока разряда в отдельной серии опытов ток в разрядной цепи был ограничен на уровне 100 А. При этом на тенеграммах разряда также была зарегистрирована микроканальная структура. Следует отметить, что в этом случае экспериментальные условия реализации разряда близки к работам $[18,19]$, где микроструктура автографа канала подробно исследована с использованием электронного микроскопа.

Полученные результаты дают основания утверждать, что возникновение микрократеров на поверхности электрода связано с наличием микроканальной структуры в разрядном промежутке. Отсюда можно предположить также наличие микроканалов и в других типах разрядов, где регистрировалась подобная микроструктура автографов [6-20].

В экспериментах не установлено зависимости параметров микроканальной структуры от материала плоского электрода. Микроструктура автографа разряда, напротив, существенно зависит от его материала. Так, в отличие от медного электрода (рис. 4) на поверхности стальной пластины присутствуют оплавленные участки размером около $100 \mu \mathrm{m}$ и более, на фоне которых выделяются микрократеры меньших размеров.

При инверсии полярности электродной системы микроканальная структура и ее динамика в целом аналогичны описанной выше. Однако в отличие от предыдущей, где микроканалы в импульсе наблюдаются практически на всей поверхности острия (рис. 2) и вблизи него распространяются преимущественно радиально, при инверсии полярности микроканалы сосредоточены в относительно узкой области диаметром около $300 \mu \mathrm{m}$. Возможно, такое расположение микроканалов объясняет и существенно более раннее (около 25-й ns) появление ударной волны на границе искрового канала. 


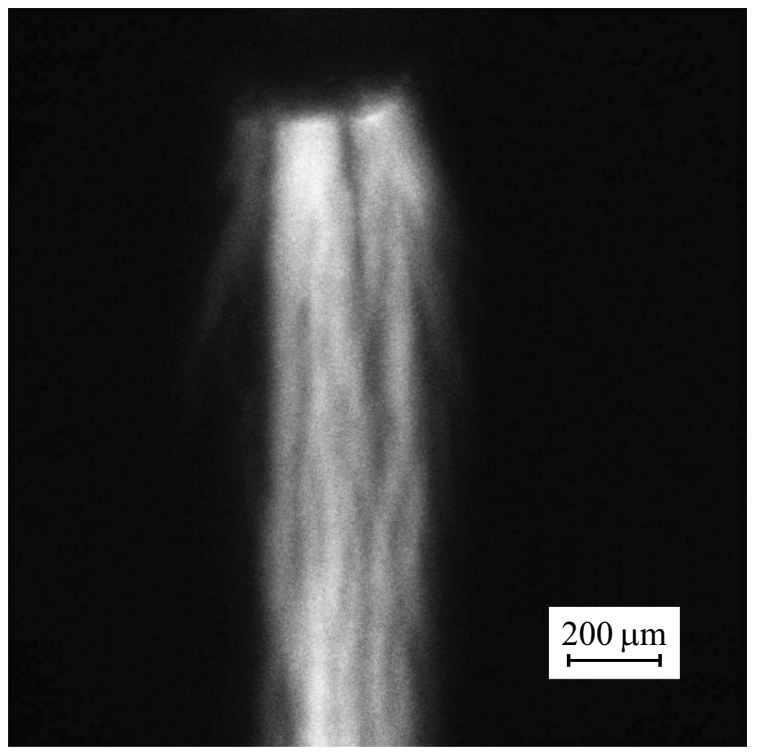

Рис. 3. Фотография свечения разряда, соответствующая моменту времени $25 \mathrm{~ns}$ от начала пробоя. Электрод-острие находится сверху.

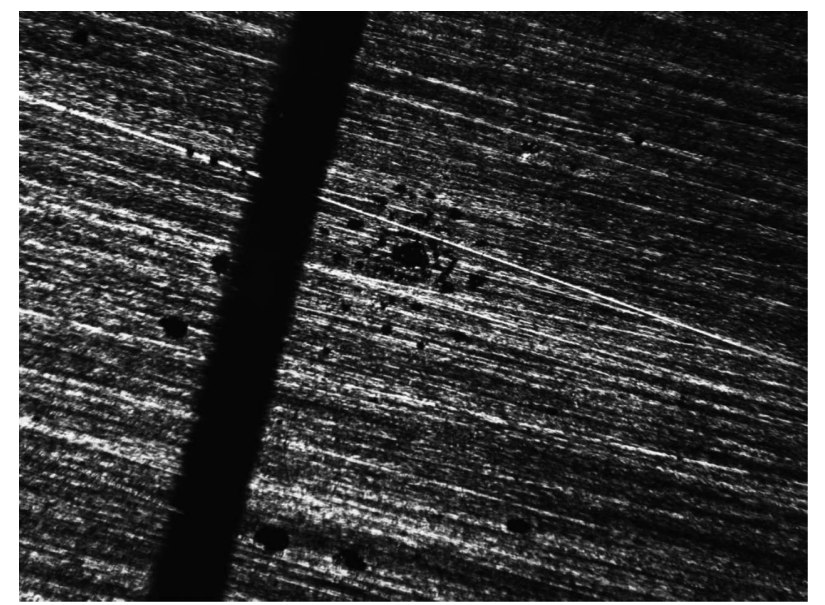

Рис. 4. Автограф разряда на поверхности плоского медного электрода. Диаметр проволочки-репера $60 \mu \mathrm{m}$.

Использование в оптической схеме ножа Фуко дает близкие результаты визуализации динамики микроструктуры разряда.

Сравним полученные результаты с данными работы [24], где также было обнаружено формирование множества нитевидных каналов диаметром от 60 до $100 \mu \mathrm{m}$ в диффузном разряде в аргоне при давлении 300 Torr в промежутке острие-плоскость длиной $3 \mathrm{~mm}$. В отличие от настоящей работы в [24] формирование микроструктуры регистрировалось спустя 100-400 ns от начала пробоя, а до этого времени разряд был достаточно однороден. Формирование такой структуры связывается с развитием ионизационно-перегревной неустойчивости [24]. Можно предположить, что указан- ные отличия в параметрах и динамике микроструктуры разряда определяются характеристиками газовой среды.

Таким образом, полученные в настоящей работе результаты в целом подтверждают развитые к настоящему времени физические модели формирования и динамики микроструктуры $[1-7,9,15,20,21]$. Согласно этим моделям, микроструктура формируется за счет неустойчивости фронта волны ионизации в фазе перемыкания разрядного промежутка. Протекание тока в микроканалах вызывает их омический нагрев, расширение и снижение концентрации газа в микроканалах. Данный эффект в ряде случаев способен обеспечить рост отношения напряженности электрического поля к концентрации газа в микроканалах до значений, достаточных для генерации в них пучков высокоэнергетичных электронов и тормозного рентгеновского излучения.

\section{Заключение}

Исследована микроструктура искрового разряда в воздухе атмосферного давления в промежутке острие-плоскость методом теневого фотографирования.

Установлено, что канал разряда представляет собой совокупность большого количества микроканалов. Микроструктура наблюдается с момента появления свечения разряда, которое раньше всего возникает вблизи острия.

Зарегистрирована динамика микроструктуры канала разряда на временах от единиц до десятков наносекунд и включающая развитие микроканалов от острия вглубь разрядного промежутка, ветвление, расширение микроканалов и их взаимодействие.

Установлено, что микроканальная структура присутствует вне зависимости от варьируемых в экспериментах материала плоского электрода, уровня тока разряда и полярности острия.

Показано, что микроструктура автографа канала разряда на поверхности плоского электрода коррелирует с обнаруженной микроканальной структурой в разрядном промежутке. Сделан вывод о наличии микроканалов и в других типах разрядов в плотных газах, где регистрировалась подобная микроструктура автографов.

Авторы выражают глубокую признательность В.И. Карелину за активную поддержку работы и плодотворное обсуждение полученных результатов.

\section{Список литературы}

[1] Лозанский Э.Д., Фирсов О.Б. Теория искры. М.: Атомиздат, 1975. $272 \mathrm{c}$.

[2] Синкевич O.A. // ТВT. 2003. Т. 41. № 5. С. 695-705.

[3] Arrayas M., Fontelos M., Trueba J. // Phys. Rev. Lett. 2005. Vol. 95. N 5. P. 165001.

[4] Rocco A., Ebert U., Hundsdorfer W. // Phys. Rev. E. 2002. Vol. 66. P. 035102(R).

[5] Luque A., Brau F., Ebert U. // Phys. Rev. E. 2008. Vol. 78. P. 016206. 
[6] Карелин В.И., Тренькин А.А. // ЖТФ. 2008. Т. 78. Вып. 3. C. $29-35$.

[7] Karelin V.I., Trenkin A.A. Microchannels in Atmospheric Pressure Pulsed Discharges. In book „Runaway Electrons Preionized Diffuse Discharges“. Ed.: V.F. Tarasenko. Nova Publishers, 2014.

[8] Буранов С.Н., Горохов В.В., Карелин В.И., Павловский А.И., Репин П.Б. // Квант. электрон. 1991. Т. 18. Вып. 7. С. $891-893$.

[9] Буранов С.Н., Горохов В.В. и др. Микроструктура токовых каналов и убегание электронов в высоковольтных диффузных разрядах атмосферного давления. Исследования по физике плазмы: Сб. науч. тр. / Под ред. В.Д. Селемира, А.Е. Дубинова. Саров, 1998. С. 39-67.

[10] Репин П.Б., Репьев А.Г. Исследование пространственной структуры токовых каналов высоковольтного диффузного разряда в промежутке проволочка-плоскость // Сб. науч. тр. / Под ред. В.Д. Селемира и А.Е. Дубинова. Саров: ФГУП РФЯЦ-ВНИИЭФ, 2003. С. 143-172.

[11] Автореф. канд. дис. Лай Гуйю. Системы импульсного электропитания и возбуждение на их основе диффузного разряда: М.: МИФИ, 2004.

[12] Перминов А.В., Тренькин А.А. // ЖТФ. 2005. Т. 75. Вып. 9. C. $52-55$.

[13] Репьев А.Г., Репин П.Б., Покровский В.С. // ЖТФ. 2007. Т. 77. Вып. 1. С. 56-62.

[14] Балданов Б.Б. // Прикладная физика. 2012. № 1. С. 64-67.

[15] Trenkin A.A., Karelin V.I., Fedoseev I.G. // High Voltage Engineering. 2014. Vol. 40. N 7. P. 2211-2216.

[16] Тренькин А.А., Карелин В.И., Шибитов Ю.М. // Изв. вузов учебных заведений. Физика. 2014. Т. 57. № 12/2. C. 284-289.

[17] Бакшт Е.Х., Блинова О.М., Ерофеев М.В. и др. // ФП. 2016. Т. 42. № 9. С. $859-870$.

[18] Карелин В.И., Тренькин А.А., Шибитов Ю.М., Блинова О.М., Ясников И.С. // ЖТФ. 2016. Т. 86. Вып. 10. C. $54-57$.

[19] Карелин В.И., Тренькин А.А., Шибитов Ю.М., Блинова О.М., Ясников И.С. // ЖТФ. 2017. Т. 87. Вып. 9. C. $1411-1415$.

[20] Buranov S.N., Gorokhov V.V., Karelin V.I., Repin P.B., Rep'ev A.G., Trenkin A.A. Generation of high-energy electrons and $X$-rays in high- voltage diffuse discharges at atmospheric pressure with interelectrode gaps up to tens of centimeters. In book "Generation of Runaway Electron Beams and $X$-ray in high pressure gases". Vol. 1. Techniques and Measurements. Editors: V.F. Tarasenko. N. Y.: Nova Publishers, 2016.

[21] Тренькин А.А., Карелин В.И., Федосеев И.Г. // Ядерная физика и инжиниринг. 2014. Т. 5. № 6. С. 524-530.

[22] Кремнев В.В., Новаковский М.В., Поталицын Ю.Ф. // ФП. 1985. T. 11. № 10. С. $1285-1290$.

[23] Козырев А.В., Королев Ю.Д., Тинчурин К.А. // ФП. 1988. T. 14. № 8. C. 1003-1007.

[24] Бычков Ю.И., Суслов Ф.И., Тинчурин К.А. и др. // ФП. 1991. Т. 17. № 2. С. 196-204.

[25] Шурупов М.А., Леонов С.Б., Фирсов А.А. и др. // ТВТ. 2014. T. 52. № 2. C. 186-197. 